\title{
Bienes muebles, hacia un nuevo concepto en la catalogación del Patrimonio Mueble
}

\section{Juan Antonio Arenillas}

Centro de Documentación del IAPH. Área de Patrimonio Arquitectónico y Urbano

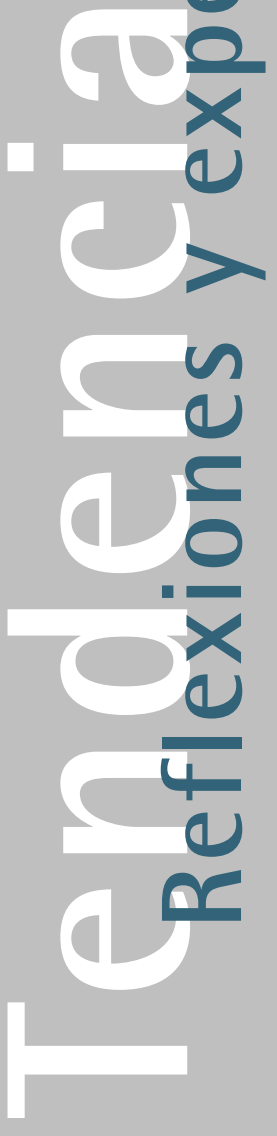

El Área de Bienes Muebles se planteó como objetivo principal racionalizar y organizar la información a fin de satisfacer las necesidades informativas de los usuarios, fomentar el conocimiento y contribuir a la protección del patrimonio mueble andaluz. A este propósito general se unió la aplicación de las nuevas tecnologías y la cualificación de los criterios y herramientas con los que se trabajaba sobre patrimonio mueble. Fruto de esa primera sistematización fue la base de datos Catálogo, la primera herramienta informática al servicio de la catalogación de Bienes Muebles en Andalucía. ' Diseñada entre 1993 y 1994, fue creada inicialmente, para recoger la información generada por el Inventario de Bienes Muebles de la Iglesia Católica, si bien, supo responder a las necesidades de otros proyectos acometidos desde el Área de Bienes Muebles del Centro de Documentación. Así, en colaboración con la Universidad de Granada, se realizó el Inventario de Bienes Muebles de dicha institución. También se estableció un acuerdo de colaboración entre el Cabildo Catedral de Sevilla y el Instituto Andaluz del Patrimonio Histórico, por el que se realizaría el inventario de sus bienes muebles, habiéndose catalogado hasta el momento las piezas de orfebrería. Al margen de estos proyectos particulares, se pudo incorporar la información de otras instituciones culturales, caso de la Dirección General de Bienes Culturales y las distintas Delegaciones Provinciales, referente a bienes muebles en sus distintos niveles de protección. ${ }^{2}$

La nueva base de datos del Sistema de Información del Patrimonio Mueble, Bienes Muebles, es fruto del trabajo interdisciplinar de tres áreas del Centro de Documentación (Bienes Muebles, Arqueología y Etnología), el apoyo del Área de Normalización, y el Área Informática que la ha desarrollado. Con el nuevo diseño se ha pretendido avanzar en la investigación de la documentación e información, profundizándose, de ese modo, en el conocimiento del Patrimonio Mueble. ${ }^{3}$ Posee una doble vocación; la de sistematizar una información básica sobre los bienes muebles de Andalucía y servir de herramienta abierta de desarrollo del Sistema de Información del Patrimonio Mueble. Puede decirse que es una aplicación abierta hacia otros módulos de información que enriquezcan y profundicen en el conocimiento del patrimonio mueble andaluz.
Otros objetivos marcados en esta aplicación se refieren a la incorporación de las imágenes que documentan gráficamente al bien y su visualización directa a través del módulo Imágenes, o a la aplicación del nuevo Tesauro del Patrimonio Histórico Andaluz (TPHA).

De mayor importancia si cabe es la posibilidad de incorporar bienes muebles desde tres disciplinas distintas: historia del arte, arqueología y etnología. Es lo que se ha denominado como Caracterización. Por lo tanto, Bienes Muebles permite la incorporación de bienes muebles artísticos, arqueológicos y etnológicos, estén albergados en instituciones culturales o en inmuebles en el territorio, pudiéndose obtener una información individual o conjunta de los bienes muebles incorporados al Sistema.

Al seleccionar cualquiera de las tres caracterizaciones la estructura de la base de datos varía en cuanto a sus módulos y campos. Esto se hace patente de momento en tres módulos: Identificación y Localización, Descripción y Análisis. En el primero de ellos, para los bienes artísticos y etnológicos se incorpora un campo, Procedencia, que para los arqueológicos pasa a denominarse como Yacimiento, añadiéndose además el Código de Intervención. En el módulo Descripción varían notablemente los campos en función de la disciplina desde la que se analice el bien mueble. Así, para bienes arqueológicos y etnológicos, se incorporan dos campos comunes, Actividades y Origen, y un tercero, Contexto Arqueológico (bienes arqueológicos) y Área de procedencia (bienes etnológicos). En Análisis, además del físico propiamente dicho aplicable a las tres disciplinas, para los bienes muebles etnológicos se ha incorporado un Análisis Funcional con cuatro campos básicos: Actividades, Agentes, Procedencia y Descripción del uso.

Además de las cuestiones ya reseñadas, Bienes Muebles supone una gran avance respecto a Catálogo, no sólo en su concepto y diseño, sino también en su concepción informática. De una base de datos que utilizaba como herramientas, Dbase IV y Clipper, se ha pasado a una aplicación que ofrece una visión de pantallas en el estándar Windows, se encuentra desarrollada en Access 97, accediéndose a ella a través de una aplicación en Visual Basic 6.0. Estas herramientas han posibilitado la implantación en el proceso de desarrollo de las metodologías más modernas de ingeniería del software, como son la orientación a objetos, la programación dominada por eventos o las técnicas de desarrollo de bases de datos relacionales.

De los avances en sus módulos y campos, así como en su nueva metodología empleada en la introducción e 
incorporación de datos, se hacen a continuación unos planteamientos básicos en el análisis de su estructura.

\section{Estructura}

La nueva aplicación presenta tres grandes funciones: Alta/Modificación, Consulta/Informes y Administración. Con ellas se pretende abarcar los conceptos de carga, actualización y edición de datos; servir al usuario como medio de información y conocimiento del patrimonio mueble andaluz, y facilitar la selección de la información a través de múltiples funciones.

A estos conceptos básicos, se añade la incorporación de una pantalla de control de las Fuentes que alimentan los registros, y que el catalogador debe cumplimentar obligatoriamente. En ella se recogen los datos referidos a la Institución, Servicio/Centro, Departamento/Área, Actividad, Responsable, Fecha y Fuentes, que da de alta al bien.

El diseño de pantalla queda dividido en dos partes bien diferenciadas: el Frame con una serie de hipervínculos o funciones, y el Contenido donde aparecen las distintas pestañas o etiquetas que dan acceso a los diferentes módulos de información.

\section{Alta/Modificación}

Bienes Muebles mantiene la idea de la creación de un código numérico para cada una de las piezas inventariadas, el cual facilita la propia aplicación al seleccionar en la pantalla de Alta del bien la Provincia, Municipio e Inmueble. Ha cambiado sin embargo su concepto ya que no es necesaria la introducción de los distintos dígitos que conforman el código. A través de esta pantalla debe comprobarse si el bien que se desea incorporar está ya incluido en la base de datos, como paso previo ineludible. Para ello se facilitan en un pequeño módulo cinco campos de búsqueda: Código, Tipología, Iconografía, Autor y Cronología. En el caso de que el bien mueble no estuviese incluido en la aplicación, seleccionaríamos la función Nueva Alta, que aparece en el Frame.

Aquí se introduce una nueva novedad respecto a Catálogo, ya que se debe incorporar la denominación del bien y la cumplimentación del módulo de Fuentes ya citado anteriormente, en el que se incorporan distintos listados normalizados en sus diferentes campos, estableciéndose una discriminación de la información en función de la Institución que se seleccione.

La base de datos presenta una estructura modular pensada para recoger de una forma organizada la mayor información posible sobre cada una de las piezas, que, en sus diferentes tipologías, componen el patrimonio histórico mueble andaluz. La función AltalModificación incorpora información sobre Identificación, Localización, Descripción, Documentación, Análisis, Imágenes, Conservación, Protección y Datos Museográficos de los bienes muebles.

\section{Identificación y Localización}

Al margen de la información cargada en el proceso de alta del bien, referida a la provincia, municipio, inmueble y denominación del mueble, este módulo se completa con información relacionada con la ubicación, ya sea habitual o temporal, el modo de acceso, público o restringido, añadiéndose nuevos campos como Visitas y Procedencia (bienes muebles artísticos y etnológicos) o Yacimiento (bienes arqueológicos), con los que se puede incorporar la provincia, municipio y edificio del que
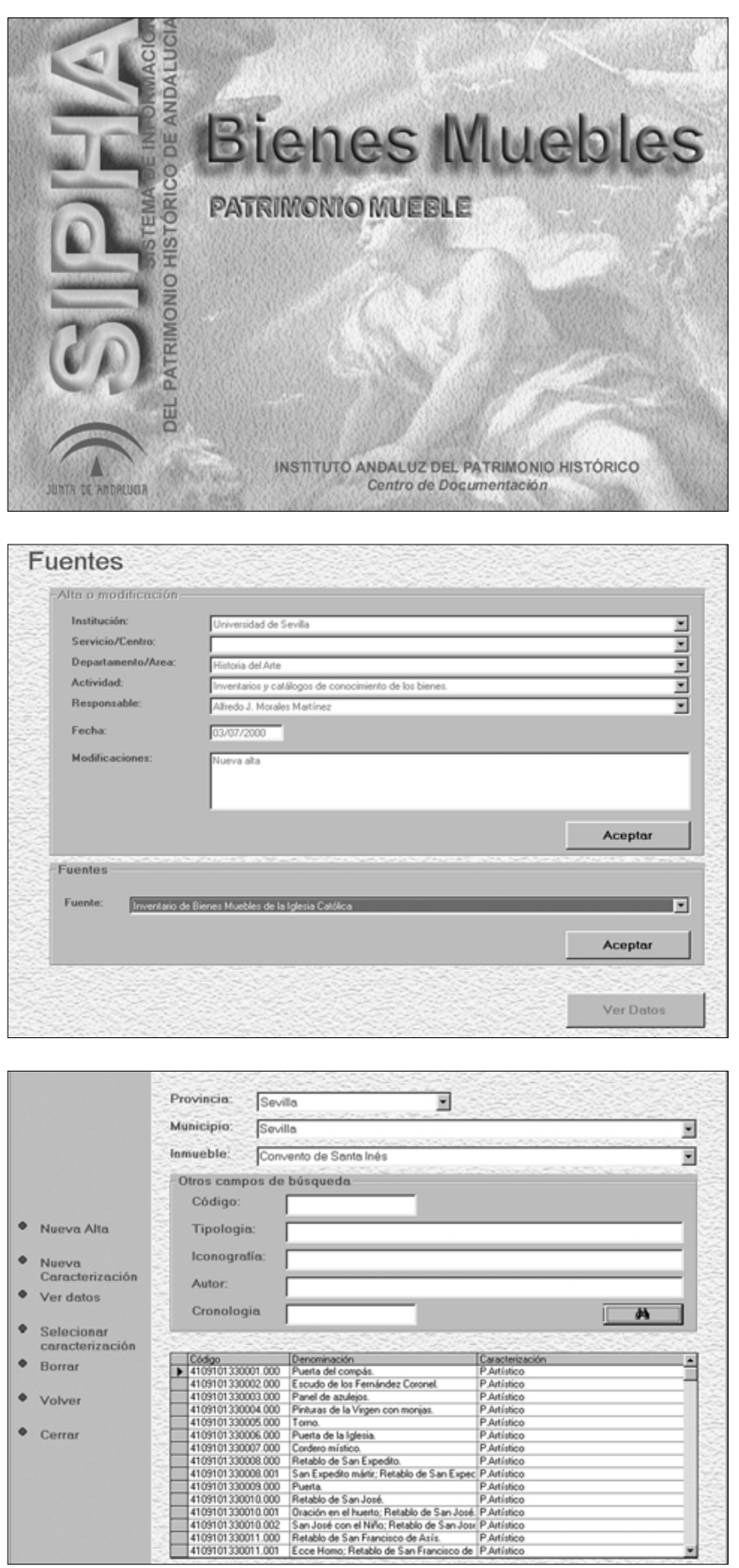

Máscara de entrada

Pantalla de Fuentes.

Pantalla de Alta del bien. 
procede el bien mueble, en su caso. Respecto a la ubicación de las piezas, se mantienen los criterios establecidos en Catálogo, siendo necesario consignar el lugar exacto del bien, describiéndose de lo general a lo particular.

\section{Descripción}

Se plantea recoger en este módulo la información descriptiva de las piezas. Por tanto, se incluyen Tipologías,
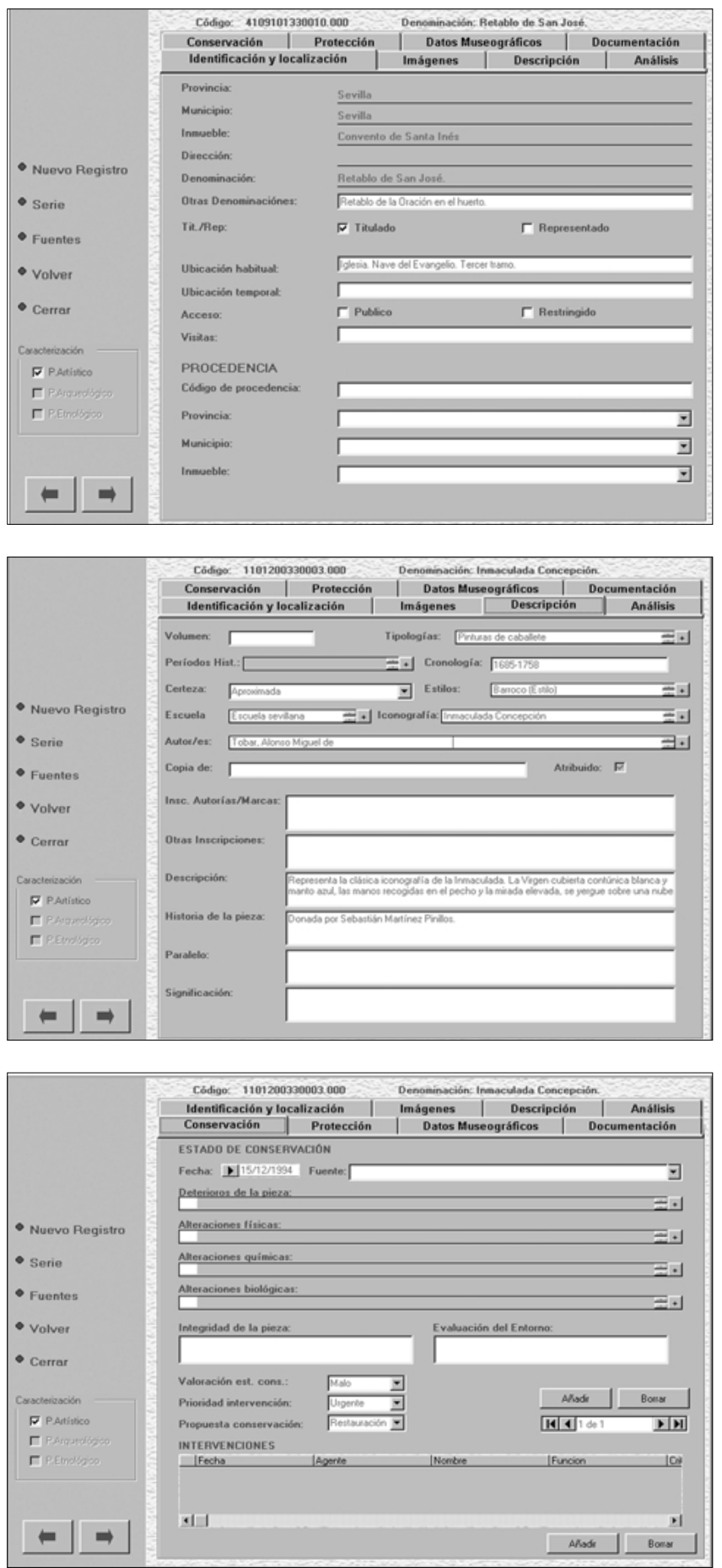

Módulo de Identificación y localización.

Módulo de descripción.

Módulo de conservación.
Períodos Históricos, Cronología, Certeza, Estilo, Escuela, Autor e Iconografía. Además se añade la descripción formal del bien y otros campos que recogen información de Inscripciones de autoría/Marcas, Otras Inscripciones e Historia de la pieza. Suponen una novedad y avance sobre Catálogo la incorporación de nuevos campos como Volumen, en el que se debe hacer referencia al número de piezas existentes de idénticas características; Paralelos, donde se deben incluir aquellas obras que guarden alguna relación con la catalogada y que aporte datos de interés para su estudio, interpretación y valoración, y, por último, Significación, en el que se destacará la importancia de la pieza en función de su significado sociocultural y su relación con usos tradicionales.

Además de estos avances hay que hacer mención especial a la nueva metodología empleada en la introducción de los términos incluidos en los listados asociados extraídos del Tesauro de Patrimonio Histórico Andaluz, en los campos Tipología, Períodos Históricos, Estilo, Escuela e Iconografía, ya que al margen de poder incorporar cuantos términos sean precisos respecto a un mismo bien mueble, la aplicación ofrece al catalogador la posibilidad de añadir nuevos términos, los cuales serán estudiados por el Área de Normalización Terminológica, previa a su inclusión definitiva.

De mayor importancia es el trabajo que se viene realizando con la citada área, en la normalización de los autores/autoridades de las piezas hasta ahora incluidos en la base de datos. El objetivo que se marca en este proceso es conseguir un listado normalizado, en el que el nombre y apellidos del autor, sus diferentes actividades y su cronología o fechas de actuación serán sus datos claves.

\section{Análisis}

Incorpora este módulo un Análisis físico con información referida a Materiales, Soportes, Técnicas, Medidas y Peso. En los tres primeros, la introducción de datos se realiza a través de diferentes cajas de listas normalizadas, permitiendo la aplicación la inclusión de nuevos términos que posteriormente serán estudiados por el Área de Normalización, previa a su incorporación definitiva.

\section{Conservación}

Este módulo ha adquirido una notable transformación. El primer gran logro se refiere a la posibilidad de incorporar cuantos estados de conservación haya tenido la pieza en su historia y que sean necesarios para su mejor conocimiento. Se añade además un campo donde se debe introducir la fuente que ha servido para cargar la información.

De gran importancia ha sido incorporar cuatro campos, Deterioros de la pieza, Alteraciones físicas, Alteraciones químicas y Alteraciones biológicas, en los que se introducen datos referidos al propio deterioro o alteración con listados asociados del TPHA, a la causa, estrato afectado y porcentaje. 
Dos campos memos, Integridad de la pieza y Evaluación del entorno, permiten conocer partes que le puedan faltar al bien y si su ubicación y relación con el inmueble que lo alberga es adecuada y conveniente.

En cuanto a Intervenciones, se presenta con un nuevo desarrollo y con la misma filosofía que Estado de conservación, respecto a la posibilidad de almacenar datos referidos a las distintas restauraciones que haya sufrido el bien mueble.

Este módulo de Conservación se presenta abierto a posteriores desarrollos. El análisis de la información contenida en los distintos expedientes de intervención implicará la sistematización de una documentación amplia que llevará, sin lugar a dudas, a la inclusión de nuevos módulos. En una primera aproximación a esa documentación, se sugiere incluir Estudios previos y Procesos de intervención como nuevos desarrollos.

\section{Protección}

En este módulo se han incorporado aquellos campos necesarios para el conocimiento del nivel de protección de la pieza, así como los de Propuesta de Protección y Justificación, para aquellos bienes no protegidos.

\section{Documentación}

Es quizás este módulo el que mayor desarrollo ha alcanzado, ya que incorpora los módulos documentales bibliográfico, documental y gráfico, y sus posibles interrelaciones. Por tanto, el modo de introducción de datos varía según se trabaje con un documento fondo o fuente. En el caso de la cita de una obra bibliográfica que contenga documentos o gráficos del bien mueble catalogado, se introducirán a través de Documentos y Gráficos relacionados, y no a través de Información Documental o Información Gráfica.

Además, en Información bibliográfica, se ha podido incorporar un listado normalizado que contiene un $50 \%$ del cómputo total de citas bibliográficas incluidas en la base de datos, una vez han sido cotejadas con los registros de la base de datos Biblos. Queda aún otro $50 \%$ de registros bibliográficos pendientes de normalizar para su definitiva incorporación al programa.

En cuanto a Información Documental, el Área de Normalización Terminológica está realizando un importante esfuerzo por incorporar cuantas instituciones sean necesarias para los distintos proyectos de catalogación coordinados por el Área de Bienes Muebles. El avance respecto a Catálogo es muy grande. La antigua aplicación sólo incorporaba unos datos muy básicos sobre los documentos. Bienes Muebles pretende con la incorporación de este módulo de la base de datos Documental recoger una mayor información sobre el documento, siempre en beneficio de profundizar en el conocimiento del bien mueble.
Por último, debemos indicar que en Información Gráfica, también se introducen, como ya normalizados, cuantos registros de la base de datos Gráfica estén relacionados con los bienes muebles que se vayan a catalogar. Este módulo de información también se presenta como nuevo respecto a Catálogo, ya que esta aplicación recogía una información muy sucinta del documento gráfico. En la nueva aplicación, se llega a recoger datos de las características de la película utilizada, del autor del documento, etc.
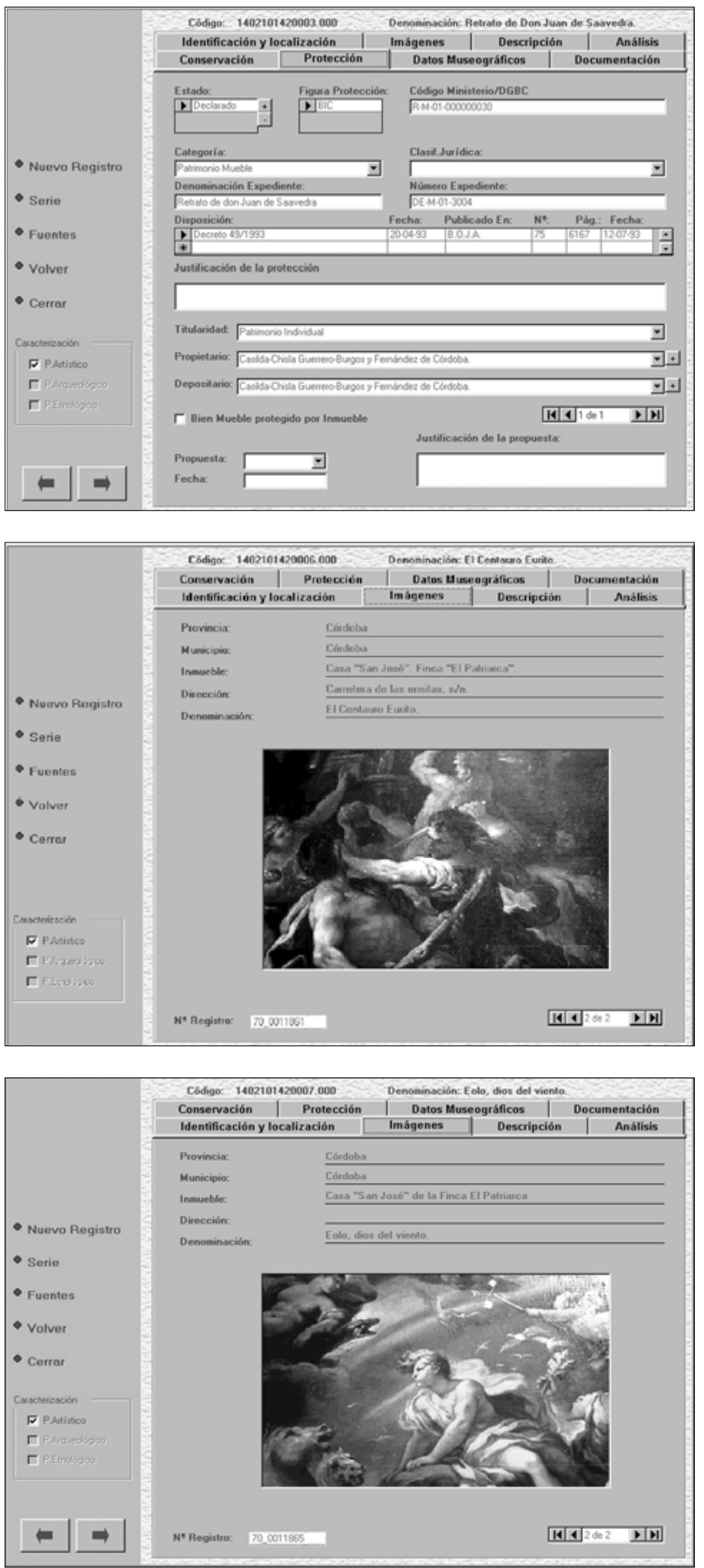

Módulo de protección.

Módulo de Imágenes. 
Existe, por tanto, una clara intención de facilitar al catalogador la labor de carga de datos en los módulos documentales, por medio de listados ya incorporados a la base de datos Bienes Muebles.

\section{Imágenes}

Un objetivo ya reseñado en las páginas iniciales de este artículo, y perseguido siempre por el Área de Bienes Muebles, ha sido la visualización directa de la/s imagen/es que documentan gráficamente al bien mueble. Con la simple introducción del CD-Rom (banco de imágenes) en el lector, la aplicación carga automáticamente las imágenes y se incorporan a este módulo, que además ofrece la particularidad de aparecer con sus campos ya cumplimentados, ya que la información la recoge del módulo de Información Gráfica.

\section{Datos Museográficos}

Este módulo incorpora una serie de campos relacionados con los bienes conservados en los Museos, ofreciendo una apertura clara a futuros desarrollos que nos permitan avanzar y profundizar en el conoci-

Módulo de Documentación Información Bibliográfica.

\section{Pantalla de Consultas /} Informes.
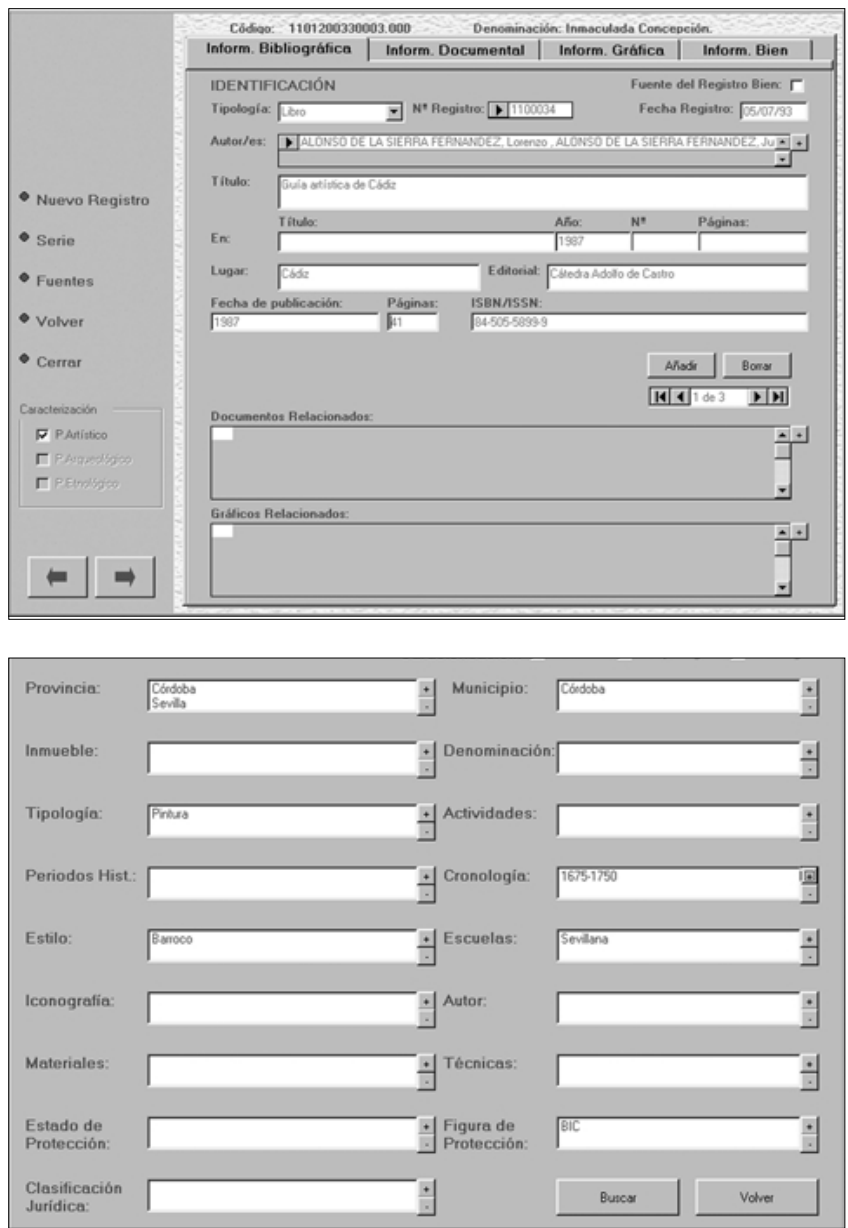

\section{Consultas/Informes}

Tiene como objetivo principal el facilitar la información de un modo rápido y ágil, permitiendo al usuario realizar búsquedas con o sin operadores. Para ello se ha establecido una primera pantalla en la que se inser$\tan$ los distintos campos opcionales de búsqueda, que van desde la propia caracterización del bien, hasta la posibilidad de localizar bienes según sus distintos niveles de protección, pasando por variables posibles sobre datos de identificación, localización, descripción y de conservación. El usuario, una vez realizada la búsqueda, podrá seleccionar la opción Informes, a través de la cual podrá acceder a los distintos listados que ofrece la aplicación, pudiendo imprimirlos directamente. La aplicación también permite a través de la opción Base de Datos, acceder a la misma y visualizar los distintos registros obtenidos en la consulta.

\section{Administración}

A través de esta función se podrá extraer e incorporar información a la base de datos, según las necesidades de los catalogadores y las propias del Área de Bienes Muebles. La pantalla presenta una serie de etiquetas en las que se recogen las distintas funciones que se pueden realizar. Así, Preparar Salida permite seleccionar información de la base de datos, pudiendo abarcar desde una o varias provincias hasta un solo bien mueble. Recuperar Entrada posibilita la recuperación de información y su carga en la aplicación. Cuestión importante en esta segunda función es la posibilidad de comprobar los datos que se deseen incorporar, como paso previo a su definitivo volcado. Reestructurar Códigos permite cambiar, reordenar y permutar códigos. Por último se incorpora una función, Borrados Múltiples, por la que se pueden eliminar de la aplicación los registros necesarios, ya sean los de una provincia completa, diversos inmuebles o bienes muebles de edificios concretos.

\section{Notas}

I. Catálogo fue desarrollada por el Área de Bienes Muebles del Centro de Documentación del IAPH, en colaboración con el Centro de Cálculo de la Universidad de Málaga y las distintas universidades andaluzas. Para conocer los criterios y la metodología empleada véase, Martínez Montiel, Luis: "La Base de Datos de Bienes Muebles del Patrimonio Histórico Andaluz", PH Boletín del IAPH, I0, Junta de Andalućá, Sevilla, pp. 46-49, y "La Base de Datos Bienes Muebles del Patrimonio Histórico Andaluz, II', PH Boletín del IAPH, I0, Junta de Andalucía, Sevilla, pp. 42-43.

2. Han sido un total de 32.000 registros de bienes muebles los incorporados a la base de datos Catálogo. El uso que ha tenido la aplicación ha sido muy diverso, sirviendo a las necesidades internas del propio Instituto, como a las de otras instituciones que han necesitado la herramienta para catalogar sus bienes muebles. Por otra parte, han sido numerosas las peticiones de información de usuarios, pudiéndose decir con claridad que esta aplicación ha cumplido con las expectativas planteadas a finales de 1993.

3. La versión I.I de Bienes Muebles ya está en uso, aunque se sigue trabajando en su desarrollo. De este modo, se puede decir que aún faltan por diseñar algunos módulos y campos relacionados con los bienes arqueológicos y etnológicos. Además, el módulo de Consultas/Informes está en fase de diseño y desarrollo, quedando aún por enlazar los distintos tipos de informes que permite la aplicación. 